\section{DE HEROÍNAS Y MUJERES. LA TRAYECTORIA CINEMATOGRÁFICA DEL PERSONAJE DE LADY MARIAN}

\author{
Gema Pérez Herrera \\ Universidad de Navarra \\ gperezh@alumni.unav.es
}

Julia Pavón Benito

Universidad de Navarra jpavon@unav.es

\section{HEROINES AND WOMEN. LADY MARIAN'S CINEMATOGRAPHIC PATH}

Cómo citar este artículo/Citation: Pérez Herrera, G. y Pavón Benito, J. (2016). De heroínas y mujeres. La trayectoria cinematográfica del personaje de Lady Marian. Arbor, 192 (779): a320. doi: http://dx.doi.org/10.3989/ arbor.2016.779n3010

Recibido: 5 mayo 2014. Aceptado: 22 mayo 2014.

RESUMEN: La revolución histórica de la mujer a lo largo del siglo XX ha tenido su correlato en un testigo de excepción: el cine. El análisis de varias representaciones cinematográficas de Lady Marian, protagonista femenina de la leyenda de Robin Hood, desde 1922 hasta algunas de las producciones más recientes permite señalar que se ha producido un cambio en el papel de lo femenino en lo heroico. Este cambio pasa por la adopción de roles y la inclusión en escenarios antaño reservados para el protagonismo masculino, así como por una progresiva masculinización de la mujer. El análisis de las representaciones realizadas en cada década del siglo XX permite también comprobar cómo el cine siempre proyecta un mensaje contemporáneo, reflejando en sus historias modelos humanos y culturales acordes con la sensibilidad de cada tiempo.

PALABRAS CLAVE: Mujer; cine; feminismo; Lady Marian; siglo XX.
Copyright: (c) 2016 CSIC. Este es un artículo de acceso abierto distribuido bajo los términos de la licencia Creative Commons Attribution (CC BY) España 3.0.

ABSTRACT: The transformation of the role of women over the course of the $20^{\text {th }}$ century can be seen particularly clearly in the cinema. The analysis of various cinematic representations of Lady Marian, Robin Hood's romantic partner, reveals the transformation in the female from feminine to heroic between 1922 and the present. This change involves Marian adopting male roles and being included in scenes that were previously reserved for male characters, together with a progressive masculinisation of women. Analysing films made in different decades shows how cinema always conveys a contemporary message, reflecting human and cultural models in keeping with the sensitivities of its viewers.

KEYWORDS: Cinema; feminist revolution; Lady Marian; $20^{\text {th }}$ century. 
El siglo XX ha sido el escenario de un importante fenómeno: la transformación del papel y proyección de la mujer en la sociedad. La revolución feminista y los cambios sociales y políticos, al compás de los acontecimientos históricos, han transformado sus ámbitos de acción y sus patrones de conducta, que han adquirido un estilo y peso diferentes en la vida pública y social.

Un testigo excepcional de estos cambios en el siglo pasado ha sido el cine, que no solo se ha limitado a crear o recoger las imágenes que han entretenido o informado a sus distintas generaciones, sino que ha participado en su educación y configuración ideológica. "Nuestra cultura proporciona una gran cantidad de narraciones (orales, escritas, audiovisuales) que nos permiten integrar y entender lo que nos rodea, narraciones que utilizamos en la construcción de nuestra propia identidad individual, en la definición de qué queremos ser y, desde luego, de nuestra identidad de género, en cómo ser hombres y mujeres en el contexto social en el que vivimos» (Sangro y Plaza 2010). De esta forma, la narrativa audiovisual $y$, por ende, cinematográfica, que refleja y revela directa e indirectamente la realidad (Ferro, 1995) se presenta estrechamente influenciada por las inquietudes y tendencias de su época (Sorlin, 2008). Por lo tanto, y partiendo de la base de que el cine, en calidad de testigo y de narrador en un tiempo histórico, es una vía idónea para el estudio de ese tiempo y de algunos de sus fenómenos (Pablo Contreras, 2001), este artículo pretende, a través de un seguimiento de una serie concreta de producciones cinematográficas en relación con la leyenda de Robin Hood, detectar los modelos y procesos evolutivos de la representación e imagen de Marian -el contrapunto femenino del protagonista-, y por extenso, de la mujer a lo largo del siglo XX.

Cabe apuntar que se conoce el debate historiográfico relativo a las relaciones y fricciones entre la historia y el cine o, también, la cuestión de la historia "narración" vs. la historia audiovisual en el plano argumentativo de sus posibles usos didácticos, documentales o descriptivos (Rosenstone, 1995; Rosenstone, 2006). Pero, teniendo en cuenta que el plano teórico de la reflexión intelectual forma parte del marco de este trabajo, y que ya viene siendo objeto de estudio por algunos de los mencionados especialistas, se ha preferido focalizar la atención sobre una historia y un personaje; el de Marian, que en cierta forma, demuestra la creación de una imagen como testimonio de la evolución de la sociedad de la última centuria (Hueso Montón, 1998).

\section{¿HISTORIA O FICCIÓN? EL PASADO AL SERVICIO DE LA NARRATIVA CINEMATOGRÁFICA}

El cine histórico, como uno de los medios más populares del siglo XX para acercar al gran público el conocimiento del pasado, se ha convertido al mismo tiempo, en una de las expresiones artísticas que mejor ha tomado el pulso a los fenómenos sociológicos y las modas de cada época. De hecho, y al igual que la narrativa histórica recoge las inquietudes intelectuales de los historiadores en diálogo con el mundo que les rodea, el drama histórico está estrechamente vinculado a las preocupaciones y moldes culturales de su tiempo. Pero mientras la producción historiográfica gira y se proyecta sobre unos círculos académicos, la industria cinematográfica está abierta al gran público, que por otro lado, demanda y se interesa por un género que le aporta algo más que aparente entretenimiento (Martínez Gil, 2013).

Un análisis de la evolución de los contenidos, puesta en escena, lenguaje argumentativo y secuencial o características de los personajes y contextos, demuestra una clara evolución en la concepción de las cintas históricas. Si al filo de los años cuarenta, en vísperas de la Segunda Guerra Mundial, Hollywood lanzó un prototipo de cine de aventuras (Robin de los bosques (The adventures of Robin Hood), Curtiz, 1938) que se perpetuó hasta los años sesenta (El Cid (The Cid), A. Mann, 1961) (Barrio, 2005); la década de los setenta dio un importante giro hacia la reflexión y la introspección de los personajes (El león en invierno (The Lion in Winter), Harvey, 1968). De forma que la atmósfera aventurera y desenfadada del cine de estudio, con sus tramoyas y decorados de cartón-piedra cedieron protagonismo ante historias que reflejaban los claroscuros de una civilización, como la occidental, que entró en una etapa de cambios profundos, e incluso convulsos

El lenguaje narrativo cinematográfico del género histórico, por tanto, y como se verá en este trabajo, no solo ha respondido a guiones que pretendían ser fieles a la realidad, sino que más bien, y al hilo de capítulos concretos de un pasado, pretendía también reflejar y lanzar un debate acerca del cuestiones que preocupaban a la sociedad, como por ejemplo, los conflictos de poderes, la manipulación de la información y la "liberación" de la mujer (Rosenstone, 1995). Habría que preguntarse entonces, con respecto a esta parcela cinematográfica: ¿sirve el marco histórico como un mero pretexto?, ¿se ha utilizado el guión al servicio de unos objetivos concretos, dentro de escenario de figuración?, ¿cuál es el objetivo de este tipo de cine? Las respuestas son muchas y con muchas, también, matizaciones. 
Ya que nuestro estudio va a estar encuadrado en el medievo, cabe realizar una breve digresión en relación a uno de los más señeros géneros de difusión narrativa de aquella época: las crónicas. Dichos relatos también jugaron un papel como medios de difusión de ideas y modelos políticos y culturales. La memoria de los hechos o personajes históricos - batallas o distintas gestas-, conformaban la gloria y la identidad de los pueblos; pero al igual que hoy, estas "historias" también incluyeron ingredientes de ficción, muy del gusto de esos momentos, con el objeto de mantener la tensión del relato y potenciar los mensajes de fondo. Asimismo, y de una manera inconsciente recogieron el escenario de intencionalidades y los argumentos contextuales a su servicio (Spiegel, 1997).

Esta mezcla de ficción y realidad cronística funcionaba y sustentaba tanto en las formas como en el fondo narrativo, al igual que hoy en día lo puede hacer a otra escala el relato de una película histórica. Esto significa grosso modo que cada generación o etapa histórica demanda ficciones acordes a sus inquietudes y necesidades sociológicas; sin perder de vista el telón de la realidad o los hechos en sí. De este modo, cabe afirmar que a lo largo del siglo XX el cine ha seleccionado determinados personajes y vicisitudes históricas, quizá porque han sido capaces de abarcar y representar los paradigmas en juego en una sociedad.

La leyenda de Robin de los bosques ha reflejado a lo largo de distintas generaciones, en cierta forma, todo ese acervo de dilemas sociales, culturales e ideológicos en conexión con los cambios operados en el siglo XX. Pero también la fabulación de la figura cinematográfica del héroe de Sherwood ha creado una imagen evolutiva, dependiendo de las distintas circunstancias históricas, sin restar un ápice a los valores morales que enarbola y que reflejan como en un espejo las más profundas aspiraciones del género humano.

En esta ocasión, no obstante, y con el ánimo de rastrear en las representaciones cinematográficas algunas pistas que nos ayuden a comprender el cambio protagonizado por la mujer en el siglo $\mathrm{XX}$, hemos elegido la figura de Lady Marian, el contrapunto femenino de la leyenda. El número de películas y series televisivas sobre su historia, realizadas desde 1908 hasta nuestros días, supera el medio centenar. De entre todas ellas hemos limitado nuestro análisis sobre quince películas del ámbito anglosajón, enmarcadas cronológicamente entre 1922 y 2010, y que han sido seleccionadas en función de su difusión y por su representatividad dentro del género.
Con el análisis de este personaje trataremos de detectar los principales cambios que se han producido en su representación. Para ello hemos tenido en cuenta cuatro ámbitos: el contexto cinematográfico de la película, qué lugar ocupa Marian en la trama, qué comportamientos y cualidades la caracterizan, y por último su relación con el protagonista masculino. Seguimos, por considerarla acertada, la clasificación que John Alberth establece para los filmes de Robin Hood (Alberth, 2003):

- Una etapa clásica en la que se forjan los arquetipos cinematográficos. Alberth marca el inicio en los años 30, aunque mencionaremos como antecedente la película realizada en 1922 por Allan Dwan.

- En la década de los 70 se cuestionan los cánones clásicos, ofreciendo una nueva mirada desmitificadora.

- La década de los 90 inaugura la última etapa, caracterizada por versiones «políticamente correctas» en las que la presencia femenina cobra protagonismo.

\section{ANTECEDENTES DEL CINE CLÁSICO: LA RECREACIÓN HISTÓRICA DE MARIAN}

Las leyendas en torno a la figura de Robin Hood han formado parte de la narrativa popular. Se forjaron a través de las baladas inglesas entre los siglos XII y XVII y se consolidaron con el resurgimiento de la narrativa de carácter histórico durante el romanticismo. Apareció entonces la legendaria imagen del bandido de Sherwood que robaba a los ricos para socorrer a los pobres y que defendía en Inglaterra la lealtad al rey Ricardo Corazón de León. Es interesante destacar que la figura de Lady Marian aparece por primera vez en una balada del siglo XVII, donde se presenta como el amor de juventud de Robin y que ante la marcha de éste se viste de hombre y acude en su búsqueda (Rey, 1999). El cine, con su gran potencial narrativo, se sumó a esta tradición a comienzos del siglo XX. Ya en 1913 se habían realizado cinco películas en torno a la figura de Robin, en las que la figura de Lady Marian aparecía como elemento básico para la trama romántica (Alberth, 2003). Las películas de esta etapa responden a los esquemas del cine silente de tinte histórico, muy narrativo y con una puesta en escena muy teatral.

El primer largometraje que aún conserva cierta vigencia es el realizado en 1922 por Allan Dwan, Robin de los bosques (Robin Hood), en el que Douglas Fairbanks interpreta al legendario ladrón de Sherwood. Esta película parece inspirarse en el espíritu de las baladas medievales y se centra en la transformación como caballero de Robin, conde de Huntingdon, caracterizado por su lealtad a Dios, al rey y a su dama. 
Tiene como escenarios la Cruzada y su lucha contra los abusos del príncipe Juan en Inglaterra.

El amor se retrata como elemento indispensable del caballero medieval: es lo que alienta su valor en el combate y el premio a sus victorias. Es también el ámbito de la historia donde la mujer, y en concreto Lady Marian, posee su papel y su protagonismo. La película nos la presenta como la "Reina del amor y la belleza», la encargada de coronar al vencedor del torneo que enfrenta a Robin con su eterno rival, Guy de Gisborne. La victoria de Robin depara un sorprendente descubrimiento, quien había mostrado su arrojo con la espada es incapaz de recoger su premio, ya que siente temor ante las mujeres. Esta divertida escena culmina con un Robin que huye espantado de decenas de admiradoras y enlaza con otra en la que el rey Ricardo anuncia que premiará a la mujer que logre conquistar al conde de Huntingdon. Las resistencias de Robin solo se verán vencidas cuando observe el acoso que Lady Marian sufre por parte del príncipe Juan. Aflora entonces la valentía de Robin, que sale en su defensa y comienza así el romance entre ellos. El rey se muestra satisfecho al ver que su paladín marcha a la Cruzada con la mitad de su corazón en la espada y la otra mitad en una doncella, pues así «su espada será más afilada».

Marian, que se queda en Notthingham, es testigo de la crueldad del príncipe Juan y toma la iniciativa de avisar a Robin. Él regresa a Inglaterra y se convierte en el proscrito que reivindica la lealtad a Ricardo, socorre al pueblo y humilla a quienes abusan de su poder. El secuestro de Marian y el acoso que sufre por parte de Gisborne motiva el ataque al castillo de Notthingham, filmado en secuencias llenas de acrobacias que serán imitadas en las posteriores películas. La paz y el orden son restaurados y Lady Marian es concedida en matrimonio a Robin por el rey Ricardo.

La figura de Marian, como hemos podido comprobar, es relevante en la historia. Ocupa su lugar como protagonista femenina de la trama romántica, en paralelo con las aventuras bélicas del héroe. Esto no hace de ella un personaje meramente pasivo o decorativo, como a veces se señala (Rey, 1999; Sangro y Plaza, 2010), sino que es clave para la configuración del héroe. La película retrata la transformación de un Robin apocado en un perfecto caballero medieval, y ahí es clave la figura de Marian, que mueve su valentía, ennoblece sus ideales y contribuye a sus victorias. Robin no hubiese vuelto a Inglaterra, ni se hubiese convertido en el personaje que todos conocemos, sin la misiva que ella envía. Cataliza la acción comportándose también como una heroína, dentro del marco en el que se desarrolla su condición de mujer.
En este marco la mujer aparece caracterizada en primer lugar por su belleza y virtud. Ya indicamos que era presentada como "reina de la belleza», ella también ha ganado su particular torneo frente al resto de candidatas. La Marian de Dwan está representada por Enid Bennet, actriz australiana que adquirió cierta notoriedad en Hollywood durante la época del cine silente, siendo esta su película más recordada. La actriz muestra el ideal de belleza propio de los años veinte, que en gran medida había creado el cine de la época. Lillian Gish, una de las primeras actrices en alcanzar el estrellato con películas como Lirios rotos o El nacimiento de una nación, había implantado un modelo de mujer de silueta lánguida y delicada, de rostro porcelanoso y muy pálido, en el que destacan las largas pestañas oscuras, los labios extremadamente maquiIlados y la melena ondulada. Las espectadoras no fueron impasibles ante estos rostros que comenzaron a hacerse insospechadamente populares, sentando los precedentes del fenómeno del star system. Lady Marian es aquí una variante medieval del estilo flapper de los años veinte, e incluso los ropajes de época acogen la moda ancha y vaporosa que estaba arrasando en Norteamérica. Son momentos de cambio para la mujer americana y europea del siglo XX; se acababa de dejar atrás la Gran Guerra, que había supuesto un paso importante en la incorporación de la mujer al mundo laboral y que también había traído consecuencias en el vestir y en el comportamiento social. Sin embargo, el ambiente doméstico aún absorbía la mayor parte de la dedicación femenina.

El escenario en el que se mueve Marian es el castillo, el hogar al que el héroe regresa y ámbito de la vida privada, necesario para la gesta pública. Aunque está excluida del campo de batalla, no se mantiene ajena al conflicto, y en todo momento se manifiesta consciente de lo que está sucediendo.

Un rasgo del personaje es su debilidad física frente a la fuerza masculina, que le impide defenderse sola cuando es atacada físicamente o acudir en rescate de Robin cuando es apresado. Pero su fortaleza moral queda demostrada a través de su resistencia a las seducciones de Gisborne o a la violencia del príncipe Juan, prefiriendo en ambos casos la muerte a la deslealtad. Hay que mencionar también como marco social en el que se desenvuelve la dependencia legal hacia su tutor, que actúa como protector y que es quien finalmente decide su destino incluso en el terreno amoroso. Este modelo de dama medieval configura el estereotipo clásico que como veremos se desarrollará en la siguiente etapa. 


\section{LA ETAPA CLÁSICA: LADY MARIAN TRAS LA CAPA Y LA ESPADA}

En 1938 Michael Curtiz dirigió la siguiente versión sobre el bandido de Sherwood, Robin de los bosques (The adventures of Robin Hood). La imagen del héroe que se ofrece en esta película debe mucho a la de Dwan, sin embargo, ha sido la interpretación del Errol Flynn la que ha quedado como el estereotipo del popular salteador (Alonso, Mastache y Alonso, 2007; Alberth, 2003). Robin se presenta desde el inicio como un héroe de carácter socarrón, valiente hasta la temeridad, galante y desinteresado. La película rescata muchos de los episodios tradicionales recogidos en las baladas y en la tradición literaria del XIX y comienza a dar protagonismo a otros personajes como Little John, Will Scarlett o Fray Tuck.

La película es uno de los ejemplos más emblemáticos del género de aventuras de capa y espada, que proliferó en el cine norteamericano durante su etapa clásica. «Hollywood encontró en Robin Hood uno de sus personajes históricos más queridos, ya que utilizando los ingredientes (reinado legendario, injusticias, rey bueno o tirano), añadiendo la habitual dosis de fantasía e imaginación de los productores norteamericanos, podía resultar un producto muy asequible e interesante para la mayoría del público, ya que todos estos materiales fílmicos son los habituales del Ilamado cine de aventuras que tantos éxitos y dividendos ha dado a la industria cinematográfica» (Barrio, 2005). Según Barrio, en estas películas que han creado el prototipo de "ambiente medieval», la impronta femenina tiene un papel clave ya que es parte del binomio armas-amor/aventura-amor que caracteriza al género. Mientras que el peso de las armas y de las aventuras recae sobre el personaje masculino, el del amor recae sobre el femenino, que se convierte en el núcleo de la trama romántica.

Lady Marian es la pupila del rey Ricardo, una dama de la corte a la que el príncipe Juan trata de casar con Sir Guy de Guisborne. Los galanteos de Robin, a quien considera un traidor y un ladrón, serán vanos hasta que la comitiva real en la que viaja Marian es asaltada en el bosque y es invitada a un peculiar banquete. Al ver las condiciones en las que vive el pueblo, Marian abrirá sus ojos al abuso normando y a la nobleza del popular proscrito. La sorpresa y el desprecio iniciales que Robin despertaba en ella se convierten en una admiración que se transformará en amor. La figura de Robin se engrandece al pasar siempre por los ojos de una mujer que le admira. Es significativa en este sentido la presencia de Marian en la mayor parte de las escenas. Su actitud adquiere entonces tintes heroicos al idear un plan para rescatar a Robin y al renunciar al amor por la noble causa de liberar Inglaterra, se queda en el castillo para actuar como espía. Cuando es descubierta se produce el asalto definitivo al castillo de Nothingam por parte de Robin y de sus hombres que culmina con la llegada inesperada del rey Ricardo. La película se cierra con el matrimonio entre Lady Marian y Robin como premio personal a la lealtad de este.

En este caso ha sido Marian quien ha evolucionado a través de su relación con Robin. Ha desafiado a la corte normanda a la que pertenecía y ha demostrado que la lealtad a Inglaterra y al legítimo representante de la corona está por encima de sus intereses personales, del amor o de su propia integridad física. Algunos autores interpretan esta película dentro de la clave histórica de lucha entre los fascismos y la democracia en la década de los treinta, el mundo occidental vivía también su propio ambiente bélico y requería quizá de esos modelos de sacrificio heroico (Alberth, 2003). La mujer estadounidense de esas décadas, hacia las que iba principalmente dirigida la película, era una mujer que seguía estando muy vinculada al hogar y la familia, como deja ver también la publicidad norteamericana entre las décadas 1930 y 1950. Aunque la entrada en la Segunda Guerra Mundial también impulsó su implicación en la vida política del país y en el mundo laboral. Sin embargo, el ideal de feminidad seguía muy asociado al modelo de esposa y madre, y a un atractivo que combinaba la elegancia de las formas femeninas con valores asociados a la delicadeza y la ternura que no eran incompatibles con la iniciativa y una gran capacidad de sacrificio, especialmente visibles en la gestión de sus hogares.

Volviendo a Robin y Marian, su relación se enmarca dentro del ideal del amor cortés, donde la mujer es objeto de admiración y de protección. Este respeto hacia la figura de la mujer solo es violado, al igual que ocurría en el filme de Dwan, por los villanos, mientras que su protección es un distintivo de la verdadera nobleza, como se refleja en el discurso inicial de Robin: «Vosotros, hombres libres, desposeeréis al rico solo para dar al pobre, cobijaréis a niños y enfermos y ampararéis a mujeres normandas y sajonas. Lucharéis por una Inglaterra libre, la defenderéis hasta el regreso de su rey Ricardo Corazón de León».

La actriz escogida para este papel fue Olivia de Havilland, una de las actrices más populares en esa década y que era la pareja cinematográfica habitual de Errol Flynn, ambos son un claro exponente de la 
dinámica del star system que ya estaba consolidado en Hollywood. Su principal atractivo radica en la femineidad que imprime al personaje. Sus atributos son la discreción, la delicadeza, la compasión y la bondad, compatibles con una fortaleza interior que la capacita para grandes ideales y sacrificios. Reconocemos aquí al personaje de Lady Marian, pero también a Melanie Hamilton, su personaje en Lo que el viento se llevó (Gone with the wind, Fleming, 1939); a Beth Custer en Murieron con las botas puestas (They died with teir boots on, Curtiz, 1941) o a Arabella en El capitán Blood (Captain Blood, Curtiz, 1935), que son quizá sus interpretaciones más recordadas. Una feminidad muy vinculada al ideal de mujer del que hablamos antes y que se puede encontrar también en la interpretación de otras actrices clásicas como Elizabeth Taylor —en sus primeras etapas-, Joan Fontaine, Mary Astor o June Allyson (Barrio, 2005). Tampoco sus espectadoras fueron indiferentes a los modelos de la pantalla. Fue precisamente en esta época clásica, sobre todo a partir de los años cincuenta, cuando el cine comenzó a vincularse de manera especial con la moda, y en consecuencia con el mundo de la imagen de la mujer. Nombres como Givenchy o Edith Head son ejemplos de profesionales que saltaron de uno al otro lado de la pantalla, vistiendo no solo a las actrices sino también a sus espectadoras.

Es interesante reseñar la aparición de otra figura femenina en la película: Bess, su dama de compañía. Realiza un papel de contrapunto cómico al caricaturizar rasgos femeninos como la coquetería o el sentimentalismo. Sin embargo, saldrá en defensa de Marian durante el asalto en el bosque ridiculizando a los hombres. Tanto Marian como ella tratan de hacer frente a los abusos con los medios que tienen a su alcance, alcanzando así un heroísmo y una nobleza propias.

Como hemos indicado, estos estereotipos en la caracterización de la historia de Robin Hood han configurado las versiones posteriores, que bien han sido fieles a la herencia clásica o bien la han subvertido proporcionando nuevas visiones. Hasta la década de los sesenta, Robin mantiene un carácter cómico y osado, junto con un alto grado de nobleza y fidelidad al rey, a su patria y a su dama. Lady Marian permanece subordinada a la trama romántica, en la que tiene un papel protagonista catalizando la acción de Robin y colaborando con la causa de los proscritos sin perder los atributos que tanto Enid Bennet como Olivia de Havilland le habían proporcionado: belleza, bondad e inteligencia; mientras que las iniciativas de acción físi- ca quedan reservadas para los protagonistas masculinos. En este sentido, destacan producciones como El hijo de Robin de los bosques (The bandit of Sherwood forest), Henry Levin, 1946, El rey de los bosques (The prince of thieves), Howard Bretherton, 1948, El temible Robin Hood (Rogues of Sherwood forest), Gordon Douglas, 1950, Cuentos de Robin Hood (Tales of Robin Hood), James Tinling, 1951, Los arqueros del rey (The story of Robin Hood and his merrie men), Ken Annakin, 1952 - producida por la casa Disney-, Un desafío para Robin Hood (A challenge for Robin Hood), C. M. Pennington Richard, 1967.

La película de Ken Annakin presenta una novedad. Marian (Joan Rice), amiga de Robin desde la infancia, al escuchar las calumnias que se desatan contra Robin y con el afán de demostrar su inocencia decide vestirse de hombre y acudir en su busca. Por el camino es asaltada por Robin, y sin reconocerse, pelearán entre sí. Este pasaje, no representado hasta el momento, tiene su origen en la primera balada sobre Marian. Es un elemento de cambio significativo, ya que introduce a Marian en una acción de lucha personal. Este episodio supuso una curiosidad aislada, de cariz cómico y sentimental, pero será un aspecto clave en décadas posteriores.

\section{"NO TIENES QUE SALVARME DE NADA": MARIAN Y LA DESMITIFICACIÓN MODERNA}

En los años setenta tienen lugar dos hitos en la representación de Marian y Robin. En 1973 la factoría Disney produce Robin Hood (Robin Hood), Wolfgang Reitherman, un largometraje animado protagonizado por animales que recoge algunos de los episodios clásicos. Marian es una zorrita cuyo protagonismo radica en la relación amorosa con Robin. Marian, encargada de entregar la flecha de oro al vencedor del concurso de arqueros, es el motivo para que Robin se arriesgue a asistir ante la oposición de sus amigos. "Recuerda -le dice Robin a Little John-, corazones pusilánimes jamás conquistan bellas damas». Es una relación que continúa caracterizada por los estereotipos del amor cortés, aunque se introducen indudables toques de modernidad y anacronismo. La dama de compañía una gallina clueca que recuerda a la Bess de Curtiz-, se muestra en clave cómica como una dama intrépida que desafía a sus perseguidores y que incluso interviene activamente en la batalla.

Sin embargo, lo más interesante de esta nueva adaptación radica en el cuestionamiento de ciertos presupuestos de la historia: Little John cuestiona por vez primera la «nobleza» de las hazañas de Robin: 
«¿Sabes Rob? Me estaba preguntando... ¿'somos los buenos o los malos? Ya sabes, con eso de robar a los ricos para alimentar a los pobres». Un simple apunte que no tendrá más trascendencia pero que revela un cierto cambio de mentalidad al revisitar el heroísmo de Robin. Ocurre lo mismo cuando Robin es condenado a muerte y Marian intercede entre lágrimas. Sorprendentemente el príncipe Juan concede el indulto y el amor es celebrado como fuerza que todo lo puede, «Te debo la vida, querida». Al tiempo que el espectador ve que no ha sido precisamente el amor lo que ha movido al príncipe Juan, sino el temor, ya que tras el baldaquino real se encuentra Little John amenazándole con una espada. El episodio de la salvación de Robin a través de la acción - nunca bélica- de Marian, que era un rasgo heroico del personaje, queda cómicamente subvertido. Estos pequeños apuntes desvelan ligeramente el cambio de planteamientos que se está produciendo.

En 1978 Richard Lester filma Robin y Marian (Robin and Marian), película de producción británica que supone un punto de inflexión. Retrata la vuelta del héroe a su tierra veinte años después de los acontecimientos que las baladas habían convertido en leyenda. Tanto Robin como el espectador revisitan la vieja historia con otros ojos. Lester quiso haber titulado su película La muerte de Robin Hood, aunque los imperativos de la producción se lo impidieron (Alberth, 2003). Basta recordar los festivos títulos de las versiones anteriores para constatar el cambio. Aunque siguen presentes rasgos como el sentido del humor y la picaresca, la película se caracteriza por un marcado carácter desmitificador. La mirada de Robin hacia su pasado y hacia la realidad presente es una mirada desencantada, que queda retratada con el par de manzanas podridas que abren y cierran la película. En las cruzadas ha perdido todo lo que pensaba que poseía: la nobleza de una misión, el heroísmo de sus acciones, la lealtad a un gran rey, las creencias religiosas e incluso el amor de una mujer.

La desmitificación se obtiene también por la vía del realismo estético, con pretensiones de realismo histórico. Por primera vez se ofrece una imagen dramática y explícita de la violencia de la guerra. El cambio afecta también a los personajes. El rey Ricardo muere como un hombre sediento de sangre y de riquezas, y esta es la versión que se generalizará desde entonces. Las aventuras de Robin también quedan en entredicho. "Todo el mundo quiere oír tus hazañas» le dirá Will Scarlett, a lo que Robin responde « iNo las hicimos!». La desmitificación alcanza también a la trama amorosa, donde se encuentra Marian. El personaje está desprovisto de cualquier estatus de nobleza, cuando Robin regresa y busca a la chica en quien reconoce no haber pensado demasiado, se encuentra con la enérgica abadesa de Kirky.

La belleza física, rasgo que en gran medida había caracterizado al personaje femenino, queda también cuestionada. Nos encontramos con una Marian ya mayor, con arrugas y vestida de hábito. Sin embargo, la elección de Audrey Hepburn como actriz contrarresta en gran medida lo anterior., contaba en esos momentos con 49 años de edad y con una trayectoria cinematográfica que la había consagrado como el estereotipo de mujer de belleza aniñada, moderna e independiente, rasgos que traslada a la caracterización de su personaje del siglo XII. Son frecuentes las reflexiones de los protagonistas acerca del paso del tiempo y de la pérdida del vigor y la belleza, junto con otras sobre el amor entendido como pasión y atracción. Supone una novedad que se trate de un romance adulto y tardío, en el que se aborda explícitamente la sexualidad de sus protagonistas

El tratamiento de estos temas, junto con la visión descarnada de la violencia y de la miseria de la guerra, son elementos característicos del cine moderno, que había comenzado a forjarse tras la Segunda Guerra Mundial en circuitos de cine de autor o de carácter vanguardista. En los años setenta, coincidiendo con la caída del código de censura en Hollywood, sus postulados se extendieron al cine de masas. A grandes rasgos, en este nuevo cine se produce un cambio en el enfoque de los temas, en la caracterización de los personajes y en la técnica cinematográfica, que reaccionan frente al clasicismo normativo que había imperado hasta entonces en la industria (Martin, 2008). Temas como la muerte, la sexualidad o la violencia, hasta entonces solamente insinuados comienzan a mostrarse con crudeza. La reacción a la tradición heredada explica también este revisionismo del que la película de Lester es un buen ejemplo. Como recoge Roman Gubern en su Historia del Cine, Lester que "constituye una excepción notable en este universo de amarguras [...], utiliza el humor y el desenfado, de estirpe surrealista, para dinamitar al igual que sus colegas las más respetables instituciones y costumbres del reino» (Gubern, 1974). La leyenda cinematográfica de Robin era una de ellas.

Históricamente son también años de grandes cambios sociales. Los conflictos de la Guerra Fría empiezan a percibirse como absurdos por parte de determinados sectores de la opinión pública. Se experimenta el auge de los movimientos pacifistas y de la anarquía 
hippie, que junto con la revolución sexual y feminista eclosionan en mayo del 68. Este es el mundo al que pertenecen los personajes de Lester, aunque caminen por un escenario medieval. El hecho de que la película centre su atención en la relación entre ellos, y haga secundarias las hazañas de Robin, dota al personaje de Marian de una mayor hondura psicológica. Aún sin salirse de la rama romántica, Marian posee una vida propia que equipara su protagonismo al de Robin. Marian es culta, con conocimientos de medicina y botánica, que gobierna una abadía y que se enfrenta en solitario al sheriff. Es una mujer de carácter, capaz de encararse con los hombres y de tomar decisiones drásticas. Los diálogos del reencuentro son el mejor reflejo de esta nueva mujer autónoma e independiente:

ROBIN: Marian... ¿Qué haces en ese hábito?

MARIAN: Vivo en él.

ROBIN: La guerra ha terminado, he vuelto y he venido a verte Marian.

MARIAN: Soy la madre Jennet y te puedes volver a Jerusalén.

ROBIN: Estás enfadada.

MARIAN: No he pensado en ti en 20 años.

Ignorándole, trata de entregarse al sheriff mientras él trata de impedirlo:

ROBIN: Puedo salvarte.

MARIAN: No tienes que salvarme de nada. No quiero verte.

ROBIN: Pues aquí me tienes. Tienes buen aspecto [...] ¿Dejarás que te lleve?

MARIAN: Dios está conmigo.

ROBIN: En las cruzadas no nos ayudó. Espera aquí.

MARIAN: ¡Es mi vida Robin!

ROBIN: ¡Eres boba!

La escena culmina con una sonora bofetada y el rapto de Marian por parte de Robin. Su relación se presenta bajo el paradigma de una lucha de sexos donde ella se ha convertido en una rival a la altura. Es una mujer ciertamente emancipada de la protección o necesidad de un hombre, no necesita ayuda para resolver sus propios problemas con la autoridad y se ufana de haber superado el amor y el deseo.

ROBIN: ¿Qué estás buscando?

MARIAN: Algún rastro de Marian o de la madre Jennet.
De alguna de ellas. Buena mujer Jennet. Le costó años de tesón vencer a la carne, miraba a los hombres y no sentía nada. ¿¿o ves?, ahora te mira a ti. Toca su mano, cógela. No importa no sentiría nada. Pienso en lo que hice, y sé que fue absurdo, querer morir porque te deseaba. Debió tratarse de otra persona.

Esta autonomía afectiva, la libertad sexual y el intento de superar la corporalidad son elementos característicos del llamado segundo feminismo, que emergió con la filósofa Simone de Beauvoir y que está en la base de la revolución sexual de esas décadas (Solé, 1995). Junto a esto, la relación que surge entre ellos es un ejemplo del llamado amor libre, para el que no hay trabas ni compromisos que entorpezcan el amar cuando se desea. El recuerdo de Marian no obstaculizó la relación de Robin con otras mujeres durante la Cruzada, ni obstaculizan a Marian sus votos religiosos. El amor es una pasión no subordinada a ninguna otra lealtad. La película termina con el "compasivo» asesinato de Robin por parte de Marian y su suicidio. Es el culmen de un amor romántico pero vacío y nihilista: «Te amo más que a nada en el mundo, te amo más que a los niños, más que a la tierra que sembré con mis manos, te amo más que a la plegaria de la mañana, más que a la paz y que a los alimentos, te amo más que a la luz del sol, más que a la carne, más que al placer, o que a un día más. Te amo más que a Dios». Ya no hay rastro del ideal medieval: ni Dios, ni rey, ni dama. Y Marian, en nombre del supuesto amor, termina incluso con la propia posibilidad de amar, que era lo único que les quedaba.

Un último aspecto que caracteriza al personaje femenino es su pacifismo, que se manifiesta en su deseo de no ofrecer resistencia a su encarcelamiento y en sus diálogos con Robin acerca de las cruzadas.

MARIAN: Mañana me entrego al sheriff. Lo haré por Dios.

ROBIN: ¿Y de qué serviría?

MARIAN: ¿Tú fuiste a las cruzadas no?

ROBIN: Por ciertas cosas es digno morir.

MARIAN: Pero los infieles a los que mataste también tenían alma. Si muero en prisión habrá sido por una buena causa, habré defendido algo y sin tener que matar a nadie. ¿Qué harás ahora?, ¿combatir al sheriff?, ¿más muertos?, ¿no estás cansado de eso?

El personaje de Lester supone una interesante reinterpretación muy acorde con el tiempo histórico de la película, y que abre la brecha para el cambio de protagonismo que experimentará Marian en la siguiente etapa. 


\section{ÚLTIMAS DÉCADAS: MARIAN TOMA LAS RIENDAS}

Una mirada a la producción cinematográfica desde la década 1990 muestra en primer lugar una diversificación de los géneros en las películas sobre Robin y Marian: animaciones, para televisión, fantásticas, parodias, documentales. Una mirada más incisiva señala que el multiculturalismo y el feminismo son algunos de los rasgos que caracterizan a las relecturas "políticamente correctas» de las versiones más recientes: "May well wonder with some trepidation what's next in store for Robin Hood films? For the moment, it seems that Hollywood will continue to pursue the feminization of Robin Hood» (Alberth, 2003).

En el año 2001 Peter Hewitt dirigió La Princesa de Sherwood (Princess of thieves), película que reconvierte la historia y hace que explícitamente una mujer, Gwyn la hija de Robin, protagonice las aventuras tradicionales (lucha por el rey legítimo, el concurso de arqueros, el auxilio de los pobres, el asalto al castillo de Nottingham). La joven se viste de hombre y desafía la oposición paterna para demostrar su valía como mujer. Ante el imperativo de quedarse en casa, ocupando el lugar que le es propio, ella suplicará que se le deje "hacer algo» o "morirá antes de vivir». La cinta está llena de alegatos en defensa de estos criterios, como la escena en la que Gwyn se encuentra con el heredero real y trata de robarle el caballo. Él se apresura a cedérselo, aduciendo que una joven no debe caminar en solitario por el bosque. Ante semejantes argumentos ella rechaza el ofrecimiento hecho solo «por la pobre razón de mi género». La escena termina con los dos sobre el caballo y ella, por supuesto, es quien lleva las riendas. Se refleja ya un fuerte cambio social, donde las mujeres no se conciben recluidas en casa ni al margen de la acción política, y asumen actividades hasta entonces masculinas. "Hay que dar en la actualidad a las mujeres un lugar que en otros tiempos no le han otorgado (sobre todo, en estos tiempos en que la defensa del género femenino ha proliferado)» (Aguilar, 2012). La imagen clásica de Marian solo se recupera ahora en las versiones paródicas, que caricaturizan la herencia recibida. Entre ellas la más conocida es Las locas aventuras de Robin Hood (Men in Tights), Mel Brooks, 1993, donde una Marian cursi e ingenua (Amy Yasbeck) hace ridículos los valores que antiguamente adornaban a la heroína.

Entre las producciones que se centran en la figura de Robin Hood las más destacadas han sido las películas del año 1991: Robin Hood, El Príncipe de los Ladrones (Prince of thieves), dirigida por Kevin Reynolds y protagonizada por Kevin Costner y Mary Eli- zabeth Mastroantonio, y Robin Hood (Robin Hood) de John Irving, protagonizada por Patrick Bergin y Uma Thurman; y la nueva superproducción del 2010: Robin Hood (Robin Hood), dirigida por Ridley Scott y que cuenta con Russell Crowe y Cate Blanchett en los papeles principales. Todas ellas suponen una relectura de la historia tradicional.

La película de Reynolds recoge la vuelta de Robin de las cruzadas e incorpora a un amigo musulmán de raza negra que será un bastión de ciencia y tolerancia frente al barbarismo medieval cristiano que se encuentran en Inglaterra. La película presenta también una fuerte carga esotérica que incorpora a la historia pactos con el diablo, lugares encantados y brujería.

La película de Irving, notablemente mejor que la de Reynolds aunque hoy en día haya caído prácticamente en el olvido, destaca sobre todo por una «realización en clave realista, tanto en los aspectos formales como el vestido, como en la preocupación por atender espacios más cotidianos y de la vida de las gentes humildes, frente al predominio habitual de lo solemne y lo heroico» (Barrio, 2005), de ahí que ofrezca más escenas en las que se desarrolla la vida de los proscritos en el bosque, a los que Robin se acoge. El acto de dar a los pobres lo que roba a los ricos se interpreta como una forma de lograr su confianza y aceptación.

Ridley Scott se inclina por una visión muy desmitificadora que indaga en los orígenes de Robin y en los episodios previos a su periodo de proscrito. Los elementos más innovadores de la trama son un trauma infantil y la declaración de una carta de libertades para los pueblos ingleses. Estos son los escenarios por los que se desenvuelve una Marian muy diferente a la que conocíamos. Sigue siendo el contrapunto romántico del héroe, pero su protagonismo aumenta fuera del ámbito sentimental. Analizaremos a continuación este giro en su protagonismo en relación con los aspectos que la caracterizaban en las versiones anteriores.

Su entrada en el campo de la acción viene acompañada por la adopción de ciertos roles que hasta el momento le habían correspondido a Robin. Se produce en cierta medida una "masculinización» de su comportamiento. La habilidad en el aire y la agilidad de movimientos que garantizaban la victoria de Robin frente a sus enemigos son ahora trasladadas también a Marian, a quien vemos cabalgar con rapidez, descolgarse de las lámparas, escalar tejados, asaltar fortalezas o trepar a los árboles. Marian sale del castillo o del bosque como hogar para integrarse en el mundo del trabajo manual e incluso en el escenario de batalla. 
Marian demuestra también su capacidad para el ataque y la defensa personal. En estas versiones empuña por primera vez el arco y la espada, no solo para defenderse de sus enemigos sino también para defender a Robin o a sus hombres. Deja de asistir a estos episodios como una espectadora pasiva y demuestra que puede valerse por sí misma a través de la fuerza física. A esto se añade el travestismo, cuando llega la ocasión la protagonista no solo se vestirá como un hombre, sino que vivirá como uno más en la cueva de ladrones (Irving), luchará contra Robin (Reynolds) y acudirá al campo de batalla al lado del héroe (Scott). Al realizar estas acciones imita en todo momento la gestualidad de los personajes masculinos, ofreciendo su particular versión a la acción y demostrando que es una compañera a la altura capaz de realizar sus mismas acciones con éxito (Bou y Pérez, 2010). El ejemplo más representativo lo encontramos en la primera secuencia de la película de Scott, que significativamente tiene a Marian como protagonista. Es una mujer ya adulta y de complexión fuerte, que aparece tomando las armas ante el ataque de unos salteadores para defender su hacienda. Es ella quien dirige la acción ante la mirada ciega de su suegro, que reivindica inútilmente ser el señor de la casa. La película nos la presenta así como una mujer de acción y ahí parece radicar su atractivo, no tanto en una belleza primorosa. La belleza por otra parte, no deja de estar presente, aunque su canon se extiende hasta una edad más adulta (Cate Blanchett tenía entonces 40 años de edad), algo que no sorprenderá a las espectadoras de nuestros días. En esta Marian atlética y acróbata, el vestuario ha reducido su espectacularidad y ha dejado paso a ropas más funcionales que le capacitan para una mayor libertad de movimientos.

Como en las películas de las décadas anteriores, Marian sufre otro tipo de violencia que la convierte en objeto de deseo por parte de sus enemigos. Es el ámbito en el que Marian sigue siendo más vulnerable y necesitada de auxilio; sin embargo comenzará a defenderse sola de este tipo de ataques, llegando incluso a matar a su agresor. Como novedad, en la película de Scott, Marian es obligada por su suegro, su tutor legal tras la muerte de su marido, a que se comporte como esposa de Robin. Ella no puede oponerse públicamente, pero sí en el ámbito privado. Esto provoca escenas de fuerte tensión en las que Marian, que se enfrenta a un Robin algo menos galante y respetuoso, debe imponerse con violencia para preservar su intimidad. Marian se presenta así como dueña y señora de sus afectos y voluntades, aunque las reglas del mundo en el que vive le impongan tutelas no deseadas o matrimonios forzo- sos. No obstante, en las tres películas la protagonista descubrirá el amor por su cuenta y será su voluntad la que finalmente determine su elección. Al final de la película de Irving, cuando se quiera sellar la paz mediante el matrimonio de Marian y Robin, ella responderá: «No voy a casarme como símbolo de la paz ni para ratificar un tratado. Me casaré con este hombre porque hace florecer la primavera en mi corazón». Queda patente que es ella quien toma y se entrega y que solo ella es intérprete de qué es el verdadero amor. Algo similar ocurre cuando en El príncipe de los ladrones Marian decide colaborar con Robin y él le pide que lo haga por su rey, ella responde «No, lo haré por ti».

En cierto sentido, las películas de esta última etapa empiezan a mostrar a la mujer como víctima del sistema social en el que se desenvuelve. Hasta este momento Marian solo se convertía en víctima cuando era atacada físicamente, pero ahora la protagonista femenina se entiende también a sí misma bajo este nuevo tipo de abuso por parte de los hombres, que le es exclusivo por su condición de mujer y al que planta cara con solitaria determinación. Las últimas adaptaciones incluyen así un nuevo reto a la larga historia de lucha contra las injusticias que encarnan los proscritos de Sherwood.

Como se puede observar, Marian ha dejado de actuar como catalizadora de una idea de héroe para convertirse en una compañera a la altura, que no solo es admirable por su belleza sino también por su capacidad para la acción, su destreza para robarle los papeles a Robin y la autonomía afectiva que demuestra en las nuevas situaciones en las que le toca desenvolverse. Es el retrato de una mujer que ha abandonado la esfera doméstica y el ámbito exclusivamente sentimental para salir al público con un papel propio, consciente de los retos y las dificultades que encuentra a su paso. Se refleja con ello el gran cambio de la sociedad contemporánea, en el que la mujer ha accedido ya al mundo político-laboral con unas libertades y capacidades análogas a las del hombre. Los efectos de la revolución sexual tienen su eco en la relación amorosa entre los protagonistas, que ha dejado de presentarse bajo la clave de la galantería cortés, para convertirse en lucha de sexos o en amor libre, siempre en un marco de igualdad. Aunque en el fondo todas las versiones siguen respondiendo al modelo de amor romántico (enamoramiento y final feliz), tan propio del cine comercial.

Pero junto a esa cierta "masculinización" que hemos descrito, en las nuevas versiones comienzan a despuntar dos rasgos inéditos hasta el momento, y que pasan a convertirse en distintivos del personaje de Marian. El primero de ellos es su fuerte conciencia 
social. En la película de Reynolds el personaje desprecia la vida de la corte y se implica en la mejora de las condiciones de vida del pueblo. En todos los casos es una mujer consciente de las desigualdades y de las injusticias sociales del momento, adopta una actitud de denuncia y no se limita a secundar la acción de Robin sino que tiene iniciativa propia. Si el personaje de Robin aparece más centrado en el enfrentamiento político, la defensa de las libertades e incluso en la venganza personal, Marian por su parte asume la atención a los desfavorecidos. Aunque esto se prefigura en las películas de 1991 será Scott quien lo muestre con más claridad a través de escenas en las que Marian trabaja en el campo junto a sus jornaleros, organiza la hacienda, educa a los furtivos del bosque e incluso planta cara a las autoridades.

La faceta maternal es el segundo rasgo distintivo. Esta nueva mujer de acción no está desprovista de esta faceta tan propia de su condición femenina. Esta se convierte incluso en el motor de su acción "guerrera" y le dota de una fortaleza original en el entorno masculino en el que actúa. Las últimas versiones, en efecto, resaltan más que nunca la faceta maternal de Marian en varias de sus escenas. Tanto en la versión de Reynolds como en la de Scott, Marian se hace cargo de los niños del pueblo o del bosque; el personaje de Cate Blanchett aparece como una auténtica madre para los pequeños furtivos y será también quien los defienda durante el ataque enemigo.

Estas novedades en el personaje femenino, unidas a la trayectoria ya conocida, demuestran que el heroísmo es en cierta medida un modelo siempre en construcción, en este caso muy vinculado a la mujer de su tiempo, y que no dejará de proporcionarnos sorpresas en el futuro.

\section{MARIAN APUNTA AL FUTURO: NUEVAS PERSPECTIVAS PARA LA HISTORIA DE LA MUJER}

Las conclusiones a las que nos conduce este recorrido por el personaje de Lady Marian, desde sus primeras representaciones cinematográficas hasta la última de las superproducciones de Hollywood en el año 2010, van más allá de las características de cada una de las protagonistas analizadas y nos llevan al campo de las relaciones entre la historia y el cine y a sus aportaciones dentro de los estudios sobre la mujer.

En primer lugar se constata que la construcción de cada una de las protagonistas está estrechamente vinculada a los valores sociales, culturales e incluso a los acontecimientos históricos que conformaron cada una de las etapas en las que se filmaron las diferentes versiones. Marian, no lo olvidemos, es siempre el modelo de heroína que los espectadores y espectadoras de cada tiempo quieren ver, la que están preparados para entender y con la que son capaces de identificarse.

Para ello, el personaje responde en cada época a los valores, actitudes o comportamientos que se consideran propios de la mujer o que se proyectan como modelo. Esta idea refuerza el papel del cine como testigo y agente de su propio presente histórico, con independencia del lugar o del tiempo en el que se ambiente la trama. Esta es una realidad que los estudiosos del siglo XX, y los de los siglos venideros, no deben desdeñar. Como se ha visto, el cine, incluso el más vinculado con la ficción narrativa, contiene siempre un retrato de su tiempo que puede iluminar de manera nueva nuestra comprensión del pasado. Eso sí, como insiste Rosenstone en sus estudios al respecto, hay que aprender a "leer" correctamente esos resquicios del pasado en la gran pantalla.

En esta línea se ha de entender la segunda de las conclusiones. Los cambios experimentados por la heroína femenina en la historia de Robin han tenido una dirección muy clara. Como hemos visto, desde la aparición del cine moderno se quiso romper el heroísmo de la diferencia para construir un heroísmo de igualdad con el personaje masculino, en el que además él era el modelo. Marian comenzó a robarle los papeles a Robin, no solo se adueñó de algunos de los atributos que clásicamente eran de él (fortaleza física, destreza con las armas, desafiante sentido del humor, autonomía, agresividad), sino también de sus acciones (liderar enfrentamientos, defensa personal, reivindicaciones contra la autoridad política y religiosa, regencia de las tierras). La valentía, la nobleza y la autonomía de Marian se comenzaron a medir en cuanto que equiparables a las de Robin, de ahí que le haya suplantado en acciones tradicionalmente protagonizadas por él y que haya "masculinizado" su comportamiento clásico.

Este cambio del personaje manifiesta el impacto de la lucha por la igualdad que ha caracterizado a la historia de la mujer en el siglo XX en todos los ámbitos: laboral, social, género..., en los que el modelo masculino ha sido la pauta y la meta. Hay también que añadir la influencia de la revolución sexual en la relaciones hombre-mujer. Los personajes más contemporáneos son el fruto de estos nuevos paradigmas, que además son también los responsables de cierta pérdida de objetividad a la hora de reconocer o juzgar el heroísmo de la mujer del pasado. Este modelo de mujer contemporánea, que es el de los espectadores 
y espectadoras de hoy, podría llevarnos a interpretar que la mujer, Marian, ha ganado protagonismo como heroína a lo largo del siglo XX. Lo analizado en las páginas anteriores nos demuestra que esto no es del todo correcto y que obedece a una visión excesivamente presentista de la evolución del modelo femenino.

¿Alguien podría decir que la Marian de Dwan o la de Curtiz no gozan de un protagonismo exclusivo y de una dignidad propia en sus películas? ¿No está acaso su heroísmo a la altura del de Robin? ¿No desempeña siempre un papel insustituible y sin en cuál el héroe no podría tampoco brillar? ¿Es acaso más heroica o más mujer la Marian de Scott que la de Dwan? No. Lo que ocurre es que simplemente sus papeles son diferentes, como también son diferentes sus contribuciones a la acción o al romance. En definitiva, es una manera distinta de ser héroe que en muchos aspectos se fundamenta en las diferencias evidentes que existen a la hora de ser hombre o de ser mujer.

Esa diferencia, tan acentuada en las películas clásicas, no llevaba asociado un menosprecio o una discriminación hacia la mujer. Al contrario, era patente, en especial en las versiones más clásicas, la idea de un respeto y de una valoración distintiva de la mujer, también por parte del héroe, siendo precisamente una de sus misiones la salvaguarda de esa dignidad. Marian además, siempre gozaba de una nobleza inherente asociada a la particularidad de su belleza física y moral, que la capacitaba para grandes acciones y que le hacía suscitarlas a su alrededor. Por lo tanto, es importante resaltar que Marian siempre ha sido una heroína, y que lo que ha ido cambiando es precisamente la forma de serlo, los valores y las actitudes que se asociaban a

\section{BIBLIOGRAFÍA}

Aberth, J. (2003). A Knight at the Movies: Medieval History on Film. New York London: Routledge.

Aguilar, D. (2012). Cine de animación y Literatura: "El protagonismo de Ximena en El Cid, la leyenda de José Pozo". VIII Congreso Internacional de Teoría y Crítica Literaria Orbis Tertius, [En línea]. [Fecha de consulta: 13 de diciembre de 2014]. Disponible en: http://www. memoria.fahce.unlp.edu.ar/trab_eventos/ev.1557/ev.1557.pdf

Alonso, J. J., Mastache, E. y Alonso, J. (2007). La Edad Media en el cine. Madrid: T\&B Editores.

Barrio, J. A. (2005). La edad media en el cine del siglo XX. Revista de la Sociedad Española de Estudios Medievales, 15, pp. 241-268.

Bou, N. y Pérez, X. (2010). Épica y feminidad en el Hollywood contemporáneo. En Sangro, P., y Plaza, J. F. La Representación de las mujeres en el cine y la televisión contemporáneos Barcelona: Laertes, pp. 42-58. ello y que responden, como hemos visto, a una comprensión de la mujer vinculada a épocas diferentes.

La última de las conclusiones nos invita a mirar al futuro. El análisis del cambio de la mujer a través del cine nos ha permitido no solo detectar los efectos de los paradigmas igualitarios en la gran pantalla, sino también ver con claridad algunas de sus fallas. ¿Han soportado Robin y Marian la igualdad?, ¿qué ha ocurrido cuando Marian se ha equiparado con él en todos los terrenos? La versión de Scott (2010), más actual y por lo tanto más directamente vinculada a nuestro tiempo, es la más significativa a este respecto. Como hemos visto, en ella el crecimiento de Marian va acompañado de un debilitamiento de Robin precisamente en los aspectos en que ella va mostrándose más fuerte y autónoma. Y junto a la masculinización de su personaje en el campo de la acción, Marian ofrece de pronto la novedad de la maternidad y del hogar como elementos característicos y distintivos. Se acentúa de nuevo en algunos detalles el atractivo de la diferencia, la necesidad de señalar lo que le es propio como mujer, de aportar algo que Robin no aportará. O al menos no de la misma manera. ¿Estamos ante el inicio de un nuevo rumbo? ¿Necesitaremos volver a reconocer aquello que se trató de superar, fruto de una ideología histórica que ha demostrado no tener la última palabra acerca de cómo los hombres y las mujeres somos y queremos ser? Vista la trayectoria ininterrumpida de nuevas versiones sobre Robin y Marian a lo largo de las décadas está claro que nos seguirán acompañando en el futuro. Como Alberth, nos queda preguntarnos ¿qué será lo próximo?

Carmona, L. M. (2006). Los 100 grandes personajes históricos en el cine. Madrid: Cacitel.

Ferro, M. (1980). Cine e historia. Barcelona: Gustavo Gili.

Ferro, M. (1995). Historia contemporánea y cine. Barcelona: Ariel.

Gubern, R. (1974) Historia del cine. Barcelona: Lumen.

Hueso Montón, Á. L. (1998). El cine y el siglo XX. Barcelona: Ariel.

Martin, A. (2008). ¿Qué es el cine moderno? Valdivia: Uqbar Editores.

Martínez Gil, F. (2013). La historia y el cine: ¿unas amistades peligrosas? Vínculos de Historia, 2, pp. 351-372.

Montero Díaz, J. (2008). La "realidad" histórica en el cine: el peso del presente. En Camarero, G., de las Heras, B. y de Cruz, V. (eds.). Una ventana indiscreta: la historia desde el cine. Madrid: Universidad Carlos III, pp. 128-138. 
Montero, J. y Paz, M. A. (2013). Historia audiovisual para una sociedad audiovisual. Historia crítica, 49, pp. 159-183. http://dx.doi. org/10.7440/histcrit49.2013.08

Pablo Contreras, S. de (2001). Cine e historia: ¿la gran ilusión o la amenaza fantasma? Historia Contemporánea, 22, pp. 9-28.

Rey, I. (1999). El Viaje de Robin Hood, de las baladas a la gran pantalla. En Caramés, J. L., Escobedo de Tapia, C. y Bueno Alonso, J. L. (coords.) (1999). El cine: otra dimensión del discurso artístico. Oviedo: Servicio de Publicaciones Universidad de Oviedo, pp. 315-329.

Rosenstone, R. A. (1995). Visions of the Past: the challenge of film to our idea of history. Cambridge Mass.: Harvard University Press.

Rosenstone, R. A. (2006). History on Film. Film on History. Harlow: Pearson Education.

\section{FILMOGRAFÍA}

Robin de los bosques (Robin Hood), Allan Dwan, 1922.

Robin de los bosques (The Adventures of Robin Hood), Michael Curtiz, 1938.

El hijo de Robin de los bosques (The bandit of Sherwood forest), Henry Levin, 1946.

El rey de los bosques (The prince of thieves), Howard Bretherton, 1948.

El temible Robin Hood (Rogues of Sherwood forest), Gordon Douglas, 1950.

Cuentos de Robin Hood (Tales of Robin Hood), James Tinling, 1951.

Los arqueros del rey (The story of Robin Hood), Ken Annakin, 1952.
Sangro, P. y Plaza, J. F. (2010). La representación de las mujeres en el cine y la televisión contemporáneos. Barcelona: Laertes.

Selva Masoliver, M. (1999). Mujeres y cine histórico. Cuadernos de la Academia, 6, pp. 179-190.

Solé, G. (1995). Historia del feminismo (siglos XIX-XX). Pamplona: Eunsa.

Sorlin, P. (2008). Cine e Historia. Una relación que hay que repensar. En Camarero, G., de las Heras, B. y de Cruz, V. (eds.). Una ventana indiscreta: la historia desde el cine. Madrid: Universidad Carlos III, pp. 19-32.

Spiegel, G. M. (1997). History, Historicism and the Social Logic of the Text in the Middle Ages. Speculum, 65, pp. 59-86. http://dx.doi. org/10.2307/2864472

Un desafio para Robin Hood (A challenge for Robin Hood) Pennington Richard, 1967.

Robin Hood (Robin Hood), Wolfgang Reitherman, 1973.

Robin y Marian (Robin and Marian), Richard Lester, 1976.

Robin Hood, el Príncipe de los ladrones (Robin Hood: Prince of thieves), Kevin Reynolds, 1991.

Robin Hood (Robin Hood), John Irving, 1991.

Las locas aventuras de Robin Hood (Men in tights), Mel Brooks, 1993.

La Princesa de Sherwood (Princess of thieves), Peter Hewitt, 2001.

Robin Hood (Robin Hood), Ridley Scott, 2010. 